\title{
Should bone be considered fascia: Proposal for a change in taxonomy of bone- a clinical anatomist's view
}

\author{
John J Sharkey * \\ Faculty of Medicine, Dentistry and Clinical Sciences, University of Chester/NTC, 15-16aSt Joseph's Parade Dorset St DO7 \\ FR6C Dublin, Ireland.
}

Publication history: Received on 19 August 2020; revised on 23 October 2020; accepted on 27 October 2020

\begin{abstract}
Fascia is the accepted term to describe integrated three-dimensional connective tissues that have failed to be described in a manner agreed by recognised anatomical authorities. It is proposed that the ambiguity concerning the seeming indefinability and lack of agreement is predominantly conceptual and partially technical. A call for the deconstruction of the word and a proposal for a change in taxonomy to include bone is proposed. Should bone can be viewed as a specialty of fascia it would make redundant descriptive terms "attaches", "origin" and "insertion". An agreed change in the definition to include bone would provide a fecund area of research. This paper proposes fascia as the original building material (mesenchyme) of embryology and therefore the true structural matrix that facilitates cellular specialty, including bone. It is proposed that it would be beneficial, to the widest disparate groups of researchers in human sciences, to include bone as fascia based on the supposition of specialty along a spectrum. Attention to structural aspects of fascia has resulted in insufficient attention being paid to the important unified tensegrity based threedimensional functionality and morphological states. A spectrum is used to classify something in terms of its position on a scale between two extreme points. Concerning fascia, the two points of opposition are hardness to softness along a continuum of specialisation emerging as arachnoid, blood, mucus, bone and other. It seems instructive to suggest that the issue concerning the seeming indefinability and lack of agreement is predominantly conceptual and partially technical.
\end{abstract}

Keywords: Fascia; Fasciategrity; Bone; Mesenchyme; Embryology; Osseofascial; Mechanotransduction; Biotensegrity

\section{Introduction}

Changes to international standard anatomical terminology is necessitated to: "correct errors in existing terms: names should not be changed unless they are wrong; corrections of perceived errors should not be pedantic; and inclusion of every minor structure should not be attempted" [27].

Taking cognisance of essential points highlighted by Neumann et al [27] it is proposed the orthodoxy and relevance concerning "fascia" should be called into question. Such a call is neither pedantic nor trivial. In the modern era the term "fascia" [e.g. to tie, to bind or a bandage] has failed to unite researchers while numerous authorities agree the term currently lacks a scientifically precise definition [1]. Furthermore, a number of authorities have expressed the need for a modern definition rather than a $15^{\text {th }}$ century characterisation and description of a "band that ties" [2]. This has led to confusion and contradiction concerning what a fascia is and what it is not. Scarpa's fascia and Camper's Fascia, for example, are not considered fascial structures in Gray's Anatomy [41 ${ }^{\text {st }}$ Ed] while several other authorities clearly include these structures as fascia [33]. Fascia is proposed as the original foundational fabric, or parenchyma, within which

\footnotetext{
${ }^{*}$ Corresponding author: John J Sharkey

Faculty of Medicine, Dentistry and Clinical Sciences, University of Chester/NTC, 15-16aSt Joseph's Parade Dorset St D07 FR6C Dublin, Ireland.
} 
specialised cells develop including muscle cells, nerve cells, liver cells [12]. Avoiding synonyms and eponyms [25] a proposal to identify location specific fascia by denoting an adverb such as "osseofascial" [bone], "neurofascial" [nerve] or in the case of blood "hemafascial" could help to resolve the issue. The focus of this article does not allow a discussion on gases which also need consideration from a biotensegrity viewpoint. Muscles and their associated fascia do not "attach" to bone but are three dimensionally continuous with bone having no clear point of demarcation [12].

Bones, or osseofascial tissues, have been described as "floating within" the softer connective tissues [49]. This raises the question where does fascia begin and where does it end? Bone viewed as a separate entity from the "muscular system" has been the norm since the days of Galen of Pergamon [129AD-c 210 AD] and possibly earlier since the time of Erasistratus [ca. 290 BC]. Yet a hint at the continuity of our form is reflected in the term "musculoskeletal system," a much-used phrase in texts including modern and older anatomy tomes [12]. In addition to cellular expression, fascia's morphology adapts specific to tensional and compressional resonances influencing and informing its assembly [30]. Fibroblasts respond to changes in tensional and compressional resonance. Such changes result in functionally responsive connective tissue facilitating specific morphology required in a precise anatomical locale [See Figure 1] emerging in a temporal specific fashion [32].

Change in forces generated within or acting upon specific anatomical locations have local and global effects through the mechanism of mechanotransduction [18]. Research by Harris et al [1980] confirms that denser bone is laid down wherever compression stress is greatest. On the other hand, the softer bone is located where least compressive load is evident. Therefore, by examining bone density it is possible to determine what location takes the most stress, and which location the least [Wolff's Law in bone]. Supporting arguments concerning bone as an integral aspect of the fascial continuum are highlighted via mechanotransducive dynamics of paracrine and endocrine functions of osseofascial tissues. The importance of osseofascial paracrine and endocrine activities on the pathogenesis of numerous degenerative diseases affecting multiple organs is of growing interest [34]. Osseofascial activities influence local and global homeostatic balance and health [31]. Osseofascial endocrine and paracrine activities influence and regulate systemic glucose, energy metabolism, reproduction and aspects of cognition and other brain functions [35]. With no internationally agreed functional definition of fascia inconsistencies arise resulting in ambiguity and diverse dissimilar definitions across the various specialist disciplines [12]. It is proposed that classifying fascia on a spectrum of hardness to softness, based on biotensegrity principles, would increase efficiency in researching sources. This would aid knowledge discovery. It is proposed that dissecting the harder component of human form (i.e. osseofascial tissues) from the softer more superficial connective tissues as separate and indistinct entities has degraded the true reality of tissue continuity [12].

The scientific community recognise bone as having a greater three dimensional complexity and interconnected biology than previously considered [46].

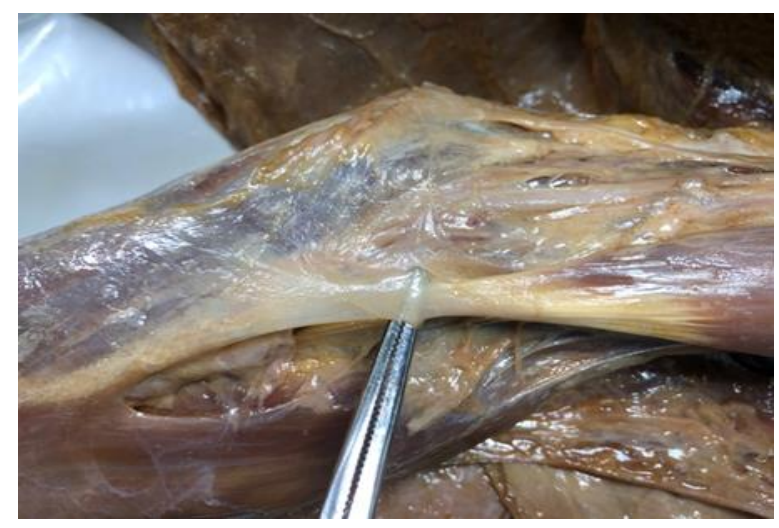

Figure 1 Fibroblasts [fascia-making cells] respond to changes in tensional and compressional resonance resulting in a functionally responsive connective tissue that facilitates the specific morphology required in a precise anatomical locale [Photograph: Sharkey, J 2019] 


\section{Embryology and Evolution-From so simple a beginning}

\section{“Internally driven forces are the algorithms of growth and form”. D’Arcy Thompson, On Growth and Form [1917].}

Humans develop from a single fertilized cell, the oocyte, during the phase known as "the period of the egg" [Larsen's Human Embryology. Fifth Edition].

The embryo emerges from the multiplication [Mitosis] of pluripotent cell genesis differentiating into many cell types resulting in numerous tissue specialities, morphologies and organs [4]. Evolution and embryology confirm that all cells, tissues, organs and organ systems have evolved, and are built from the bottom up, from the micro to the macro [Gilbert.2000]. Self-constructing embryo's respond continuously to externally but mostly internally generated forces resulting in temporally guided adaptations and morphological expressions described as "diagrams of underlying forces" [3]. Gravity played little or no role in the genesis of human embryology [29]. In the initial stages of embryology bones begin as cartilaginous pre-existing mesenchymal tissue that crystalizes into a harder modification, containing soft matter within their more crystalline arrangements [6].

At the microscopic level overlapping expression gradients increase or decrease tensional and compressional forces. Such forces lead to the production of morphogen's including sonic hedgehog [SHH], bone morphogenetic protein [BMP] and fibroblast growth factor [FGF]. Morphogen's are essential in cell growth, differentiation, and organogenesis [1]. In a report in Nature in 2018, real-time histological imaging using confocal laser endomicroscopy [pCL] identified a reticular pattern within fluorescein-filled sinuses that, previously, had no identified correlation [40]. Fibroblast cells were found to be present extensively in tissues subjected to intermittent or rhythmic compression including the urinary bladder, the gastrointestinal tract, the peri-arterial soft tissue and peri-bronchial tissues [40]. Longitudinal bone is negatively regulated by Fibroblast Growth Factors [FGFs] [24]. Muscle cells exert force on their associated fascia which in turn transmit omnidirectional force to the osseofascial tissue (i.e. bone) resulting in changes in physiology, metabolism and motion. Hypothalamic sensing neurons and glial cells activate endocrine and neuronal systems producing new physiological states along an informational fascial highway bone to brain and brain to bone [36, 37].

\section{Tensegrity in biological structures}

Inventor and futurist R. Buckminster Fuller compressed two words, namely tension and integrity, thus creating a portmanteau, or hybrid, "tensegrity" [20].

Fuller described tensegrity as "Islands of compression inside an ocean of tension" [Figure 2].

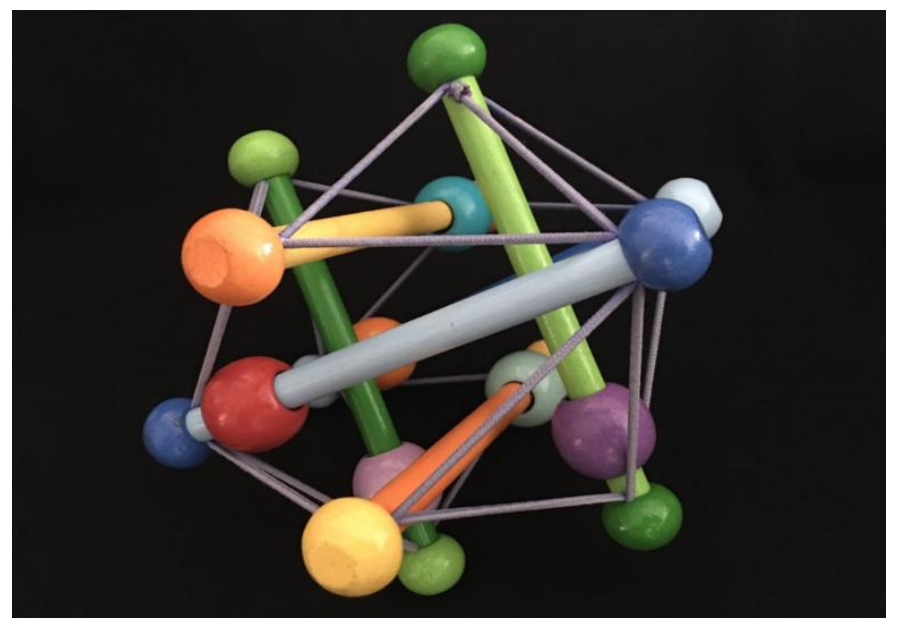

Figure 2 Tensegrities are composed of two members. One a discontinuous compression member [or strut] and one a continuous tensional member (the wire or elastic band). Note that none of the struts are touching and the space between the struts is maintained by the algorithm provided by the combined tension and compression forces. [Figure: Sharkey, J 2019]. 
Tensegrity is an architectural structural principle comprising of two force members, namely tension [continuous]. and compression [discontinuous]. Compression is provided by struts, dowels, or bars representing the discontinuous elements [20]. Macromolecules, cells and all biological tissues are constituted upon tensegrity architectural principles [16].

Biotensegrity refutes the argument that the skeleton provides a frame for the soft tissues to hang upon. A $21^{\text {st }}$ century view states that living tensegrity structures are integrated pretensioned (self-tensioned) continuous myofascial networks with floating compression struts (skeleton) in continuity within the structure [4].

To construct a biologic organism on the principles of tensegrity, a tensegrity truss must be linked in a hierarchical and heterarchical construction, starting at the infinitely small sub cellular component. Importantly, it must have the potential to build itself [3]. The structure would be one integrated tensegrity truss that evolved from infinitely smaller trusses that could be both structurally independent and interdependent at the same time. Ingber [16] described this truss as the icosahedron [Fig 2c].
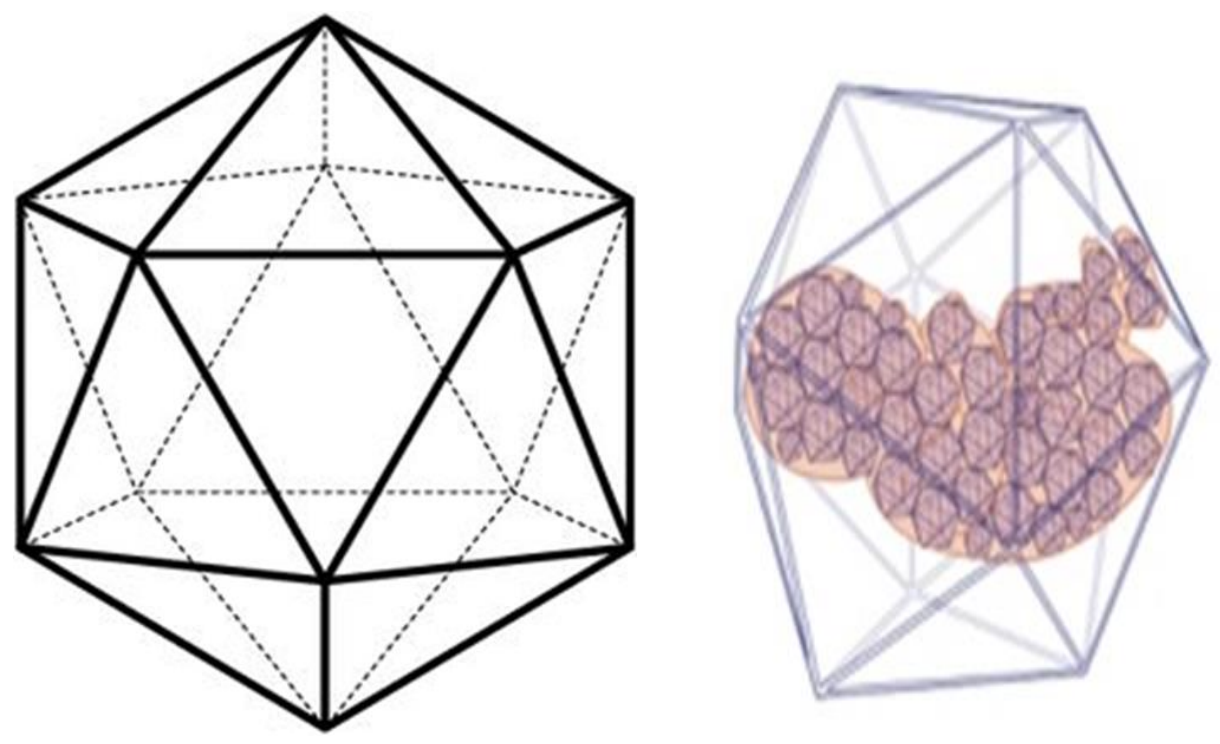

Figure 2c and Figure 2d Icosahedron [Sharkey, J. 2015. Artist Amanda Williams]. The Icosahedron [Fig 2c] is a solid figure with twenty plane faces. The faces of a regular icosahedron are equilateral triangles. Figure $2 \mathrm{~d}$ is Sharkey's Icosahedron baby providing an image of the heterarchy of tensegrity within tensegrity from the micro to the macro.

In the living body, the compression element is often, but somewhat erroneously, compared with bones. The tensional component creates a contiguous tensional network, or pre-stress, that supports the discontinuous elements in space [3].

This tensional element is most often associated or analogised with fascia. In the human construct rather than two components it has been suggested that only one construct exists along a continuum with multiple embedded cellular specialities [2]. This living construction material supports phase change modifying its role as a tension or compression generator unlike a non-living, man-made tensegrity structure. In the biotensegrity construct it is impossible to separate bone and its continuity with fascia without using a scalpel or similar [39].

Research in the 1980's [2] motivated by promising studies in the 1970's [11] led to the discovery of transmembrane cell adhesion proteins. Cell adhesion proteins are, effectively, matrix receptors providing a physical connection and continuity between the extracellular matrix and the cytoskeleton [11]. Similar to the original use of the word 'fascia', integrins "tie" the matrix to the cells cytoskeleton.

In effect, integrins are capable of sensing, communicating and inducing intracellular signalling pathways in the extracellular matrix [10]. This provides a molecular bond that serves as a multi-directional hub for the transmission of signals between cells and their environment called "mechanotransduction".

Mechanotransduction explains the mechanisms of cellular activity expressed as non-linear, omni-directional mechanical forces converted into physiology and metabolism via electrochemical communication [16]. The complexity 
of tensegrity structures leads to non-linear behaviour which is a critical aspect of biotensegrity [39]. Some authorities have suggested it is now time for a radical shift from Descartes $17^{\text {th }}$ century model of living organisms as perfect mechanical systems to a modern conceptual systems theory framework [4]. Observations made by Vesalius, Borelli, Descartes and other great pantheons of the Renaissance period have led to a linear, mechanistic view of human form and function, a view more suited to man-made solid structures [3]. Confirmed by Newton's mathematical laws and differential calculus this view remains prevalent today. Hence the "conceptual" problem associated with defining fascia.

Man-made solid bodies are constructed from man-made objects including levers, pulleys, screws, millers wheels, inclined planes, bolts, pin-joints all made from hard matter (48). Such man-made objects are constructed upon the rules of gravity as gravity is the algorithm that dictates and guides their assembly [1]. Hence the technical issue associated with fascia specifically, and anatomy generally.

Such construction materials and algorithms are not required in embryogenesis as humans self-construct within the confines of a fluidic tensegral environment, using soft matter, virtually free from gravity [2]. Unlike a man-made solid a living body does not, in the classical sense, have "a part", "a lever" or "a pin joint" [43].

In classical anatomy a bone is viewed as a discrete structure isolated from all other bones in the body [9]. Living constructs constitute a continuity of form that is continuous without disruption [20]. Since the 1500's, and earlier, the human skeletal system has been considered as detached, discrete, fragmented and separate from muscles, internal organs and fascia.

This view has promoted a model that focuses on the 'part' as opposed to a model focusing on the 'whole' [20]. This in turn has led to attempts at describing fascia continuity and mechanotransducive forces using train and chain analogies [15]. Critical unresolvable problems arise with chain and train metaphors and models as they are essentially linear. Descriptions of myofascial meridians, based on linear train tracks, offer simple to describe linear relationships between fragmented "parts". While such models provide aesthetically, verbally and even intellectually satisfying explanations they contradict biotensegrity principles [44]. This is also true of Borelli's model of parts, pin-joints and levers. In a chain model it is easy to appreciate that if one link within the chain breaks it renders the entire chain inoperable. Any damaged element within a living tensegrity results in a functional adaptation [45]. Popular chain and train analogies are evidentially linear based models working from a point to point postulate, whereas biotensegrity is non-linear, omnidirectional, continuous [4].

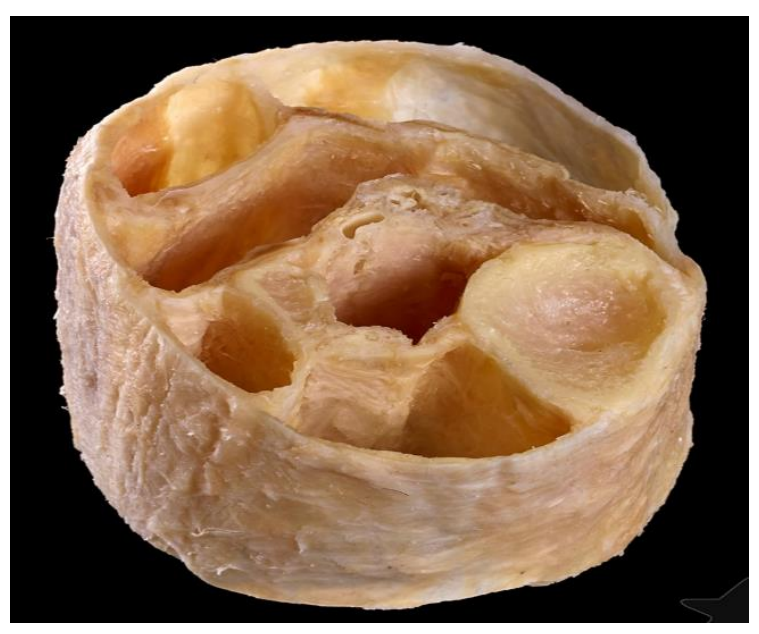

Figure E. Inside out anatomy. 
This unique image [Fig E] is what clinical anatomist John Sharkey calls "inside-out anatomy". For the first time plastinated anatomical specimens clearly demonstrate the continuity of the osseofascial system. While the muscle protein has been removed in this image it is clear to see that the associated fascia does not "attach" to bone but is three dimensionally continuous with bone having no clear point of demarcation.

This powerful image (with permission from von Hagen's Plastinarium/FNPP] reflects complex networks of fascial patterns of organisation reflecting a systemic anatomy of continuity, condensation and specialisation.

\section{4. "Real Skeletons"}

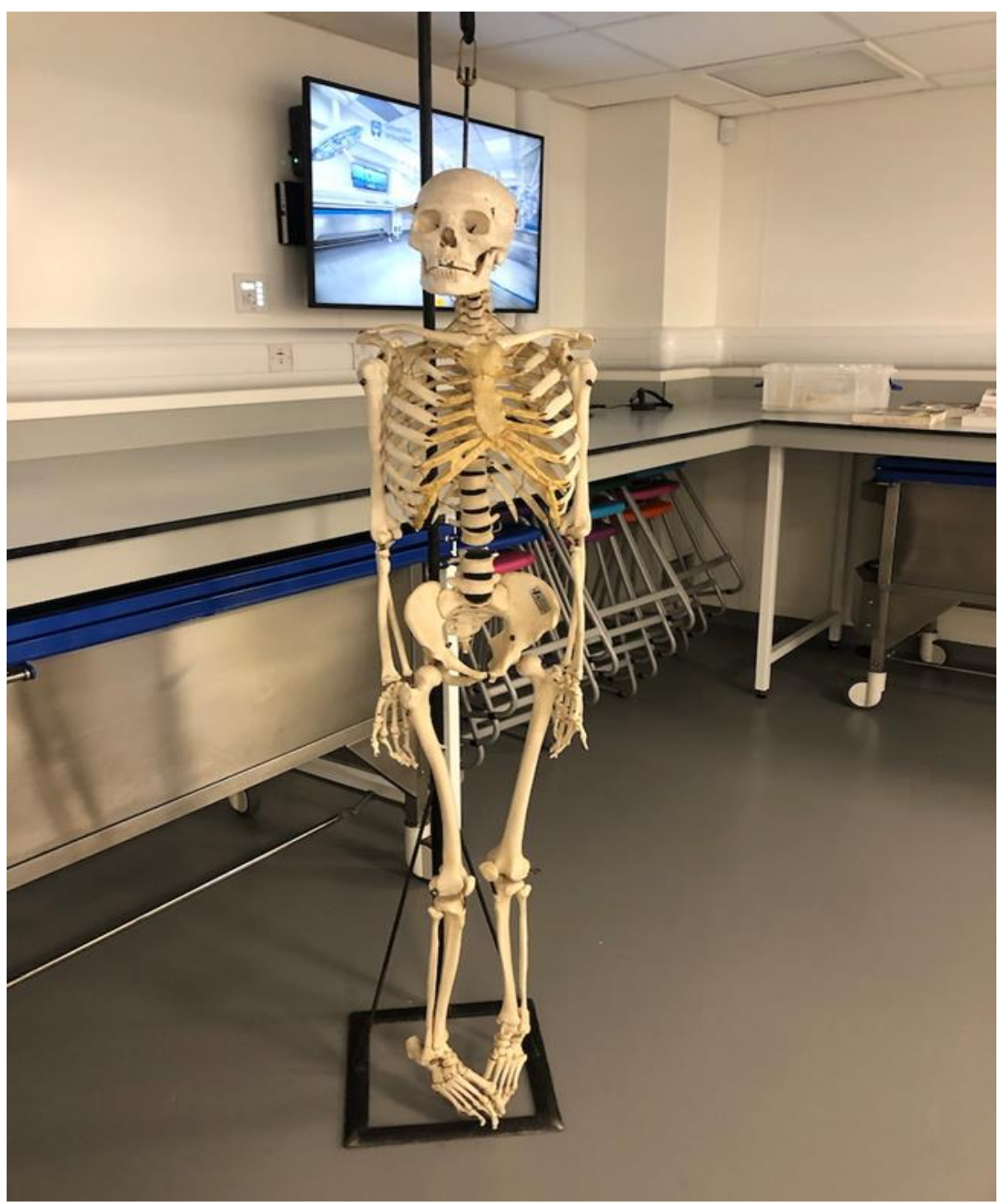

Figure F "A real skeleton”. Photograph: Sharkey, J. 2019

"Real skeletons" [Fig F] influence a student's overall impression concerning the reality of bone. Thin section transmission electron microscopy and morphometry informs us concerning the composition of living bone [14]. Bone comprises $60 \%$ hydroxyapatite, $10 \%$ bound water with collagen type 1 proteins making up most of the remaining $30 \%$. Much of these components are missing in so-called "real skeletons" seen in departments of anatomy making them hard, brittle, stiff and lacking pliability [41]. Connective tissues take on unique morphologies specific to developmental pathways ordered in a precise time and location specific manner [42]. The cellular content of bone is located in the lacunar space surrounded by the mineralized bone matrix [21].

Cytoplasmic dendrites protruding from mechanoreceptive multifunctional osteocytes, residing in the canalicular network, communicate via force transmission to and from the periosteal tissue and beyond the osseofascial 
microenvironment. Mechanical transductive forces are translated into a surge of biological remodelling by translating mechanical forces into chemical signalling [28].

Researchers no longer view bone as a passive tissue upon which the skeletal muscles hang [25,43]. Connective tissues, including bone, take on unique morphologies specific to developmental pathways ordered in a precise time and location specific manner [42]. Bone physiology is the result of mechanical stimuli providing the synergistic chemical elements necessary to coordinate cellular functions [22]. Several researchers have highlighted the inter-regulatory function of bone and adipose tissue regulation [22]. Degradation of metalloprotease enzymes and collagen synthesis increase with mechanical loading by way of force transmissions. Due to the structural hierarchy of bone its many properties and complex structure requires a multi-level appreciation of its organisation [14]. Moreover, researchers from allied, but disparate, biomedical disciplines highlight the scope and array of autocrine and paracrine osseofascial activities [47].

Fascia originates predominantly from the mesoderm with contribution from neural crest cells of the ectoderm (48). According to embryologist Blechschmidt the mesoderm reveals itself as a connective tissue - the mesenchyme [25].

This mesenchyme gives rise to connective tissue specialisation including cartilage, bone, blood (and blood vessel endothelium), the dermis, muscles (skeletal, cardiac and smooth) [7]. Restraining our vision concerning the ubiquitous nature of this continuous fascial net risks reducing the true connectivity of human form. Mesoderm is the middle condensation of the trilaminar embryological laminae comprising of the so-called ectoderm, mesoderm and endoderm.

While the focus of this article is on bone, the visceral organs integrate structurally and physiologically into this same system. There are no limb segment boundaries, so the smaller bones and joints of the hands and feet fully integrate into the biotensegrity model. The spine is a tensegrity structure that integrates with the limbs, head and tail and also to the visceral system [4]. A change of tension anywhere within the system, such as the mid back, is instantly signalled to everywhere else in the body chemically and mechanically. There is a total body response by mechanical transduction [16]. A biotensegrity works equally well right side up, upside down, in the sea, land, in the air or in space. Biotensegrity resolves many of the inadequacies of present biomechanical models.

Based on current criteria, it is difficult to defend not including bone within a wider definition of fascia [12]. Fresh frozen cadaver images [Fig G] of the fascia profundus at the macro level reflect the fractal microvacuolar structure while revealing an icosahedron like [tensegrity] composition where fractal elements inter-relate, creating a body wide framework or network. As a tensegrity based structure it is able to change/maintain shape within a fluid base allowing deformation followed by a return to its original state, whilst maintaining volume [16].

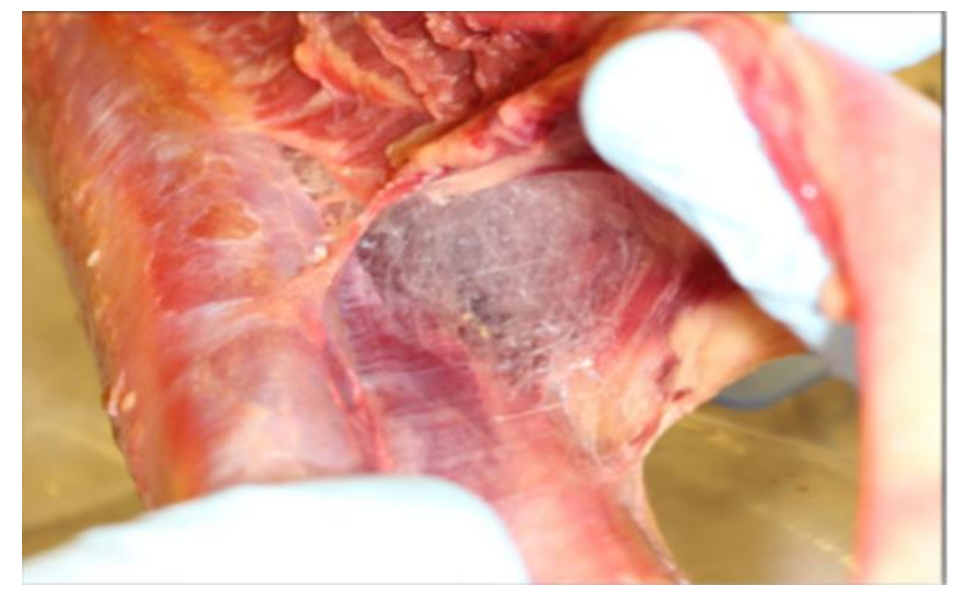

Figure G Providing a tensioning force to the tissues of the anterior forearm, on a fresh frozen cadaveric specimen, Sharkey, J., highlights the fractal, chaotic arrangement of the deep fascia. [Photo by Sharkey, J. 2010]

The visceral organs integrate structurally and physiologically into this system. There is a total body response by mechanical transduction. The structure works equally well in water, on land or in space. It resolves many of the inadequacies of the present biomechanical model. 


\section{Conclusion}

Letting go of outdated models, even in the light of $21^{\text {st }}$ century evidence, is not easy. Para-phrasing nuclear physicist Serge Gracovetski, speaking on a different but allied anatomical topic, he states that concepts such as this survive even against the contradictions they generate and that this is testimony to the matchless capacity of the medical community to keep alive an idea that has gained popularity in spite of the fact that experiment has ruthlessly annihilated its authority [Fascia in the Osteopathic field. 2017]. Such a comment is worthy of consideration in this specific proposal that bone is fascia. Evidence concerning the intimate continuity of deep fascia and bone is an undeniable reality witnessed by every clinical anatomist and surgeon while supported by gold standard, peer reviewed research. For example, Avison [3]. points out "Guimberteau and Delage [2012], Huijing and Baan [2001] and van der Wal [2009], have shown through their research that, boundaries in the body are artificial, arbitrary, descriptive conveniences" [3].

\section{Compliance with ethical standards}

\section{Acknowledgments}

I wish to express my sincere gratitude to Stephen Levin, MD for his generosity for sharing pearls of wisdom over many years.

\section{Disclosure of conflict of interest}

Author declares no conflict of interest.

\section{References}

[1] Francis-West PH, Robertson KE, Ede DA, et al. Expression of genes encoding bone morphogenetic proteins and sonic hedgehog in talpid (ta3) limb buds: their relationships in the signalling cascade involved in limb patterning. Dev Dyn. 1995; 203(2):187-197.

[2] Hynes RO. Integrins: a family of cell surface receptors. Cell. 1987; 4:n549-554.

[3] Avison SJ. YOGA, FASCIA, ANATOMY and MOVEMENT, Handspring, 2020, 2nd Edition. 2020.

[4] Sharkey J. Biotensegrity- The Structure of Life. Chapter 8, Pages 99-113 in Fascia, Function and medical Applications. edited by Lesondak, D., Akey, M, A. CRC Press, Taylor and Francis Group. 2020.

[5] Rydze R, Schutt A, Gibbons W, Nodler J. Gravity and embryo development. Curr Obstet Gynecol Rep. 2017; 6: 5154.

[6] Gilbert F. Scot. Developmental Biology, 6th edition. Sinauer Associates. 2000.

[7] Mobasheri A, Csaki C, Clutterbuck AL, Rahmanzadeh M, Shakibaei M. Mesenchymal stem cells in connective tissue engineering and regenerative medicine: Applications in cartilage repair and osteoarthritis therapy.histol histopathol. 2009; 24: 347-366.

[8] Schleip R, Jager H, Klingler W. What is 'fascia'? A review of different terminologies. Journal of Bodywork and Movement Therapies. 2012; 16: 496-502.

[9] Stranding S. (Ed.) Gray's Anatomy: The Anatomical Basis of Clinical Practice, 41st edition. Churchill Livingston, Edinburgh. 2016.

[10] Kechagia JZ, Ivaska J, Roca-Cusachs P. Integrins as biomechanical sensors of the microenvironment. Nat Rev Mol Cell Biol. 2019; 20(8): 457-473.

[11] Hynes RO. Cell surface proteins and malignant transformation. Biochim Biophys Acta. 1976 Apr 30; 458(1): 73107.

[12] Sharkey J. Regarding: update on fascial nomenclature - an additional proposal by John Sharkey MSc, Clinical Anatomist. Journal of Bodywork and Movement Therapies. 2019; 23: 6-8.

[13] Rubin MA, Rubin MA, Jasiuk I. Study of the hierarchical structure of C57BL/6J and C3H/HeJ mice trabecular bone. Bone. Jul 2004; 35(1): 11-20. 
[14] Tzaphlidou M. Bone architecture: collagen structure and calcium/phosphorus maps. 2008. Journal of biological physics. 34(1-2): 39-49.

[15] Myers T. Anatomy Trains. Fourth edition. Myofascial Meridians for manual \& Movement Professionals. Elsevier.

[16] Ingber DE. Tensegrity-based mechanosensing from macro to micro. 2008 Prog Biophys Mol Biol. 97(2-3): 163179.

[17] Schleip R, Gabbiani G, Wilke J, Naylor I, Hinz B, Zorn A, Jäger H, Breul R, Schreiner S, Klinger W. Fascia Is Able to Actively Contract and May Thereby Influence Musculoskeletal Dynamics: A Histochemical and Mechanographic Investigation. Front. Physiol. 02 April 2019.

[18] Harris AK, Wild P, Stopak D. Silicone rubber substrata: A new wrinkle in the study of cell locomotion. Science. 1980; 208: 177-179.

[19] Fronius M, Wolfgang Clauss, Althaus M. Why do we have to move fluid to be able to breathe? 2012. Frontiers in Physiology. Review Article, published. 22 May 2012.

[20] Sharkey J. In: Fascia in Sport and Movement 2nd Edition. Schleip, R. Handspring Publishing. 2020.

[21] Rocheford GY, Pallu S, Benhamou CL. Osteocyte: the unrecognised side of bone tissue. Osteoporos Int. Sep 2010; 21(9): 1457-69.

[22] Shi YC, Baldock PA. Central and peripheral mechanisms of the NPY system in the regulation of bone and adipose tissue. Bone. 2012; 50(2): 430-436.

[23] Kumka, Myroslava, Jason Bonar. Fascia: a morphological description and classification system based on a literature review.The Journal of the Canadian Chiropractic Association. 2012; 56(3): 179-91.

[24] De Luca F, Baron J. Control of Bone Growth by Fibroblast Growth Factors. 1999. Trends in Endocrinology and Metabolism: TEM. Mar1999; 10(2): 61-65.

[25] Wal JC, van der. The Architecture of the Connective Tissue in the Musculoskeletal System - An Often Overlooked Functional Parameter as to Proprioception in the Locomotor Apparatus. Journal of Therapeutic Massage and Bodywork (IJTMB). 2009; 2(4): 9 - 23.

[26] Band Karin RM. The Names of the Parts. The quest for a unified anatomical terminology. In: Équivalences, 33e année-n¹-2, 2006. La traduction médicale, sous la direction de Christian Balliu. 15-32.

[27] Neumann E, Paul Gest R, Thomas Tubbs R, Shane. The principles of anatomical nomenclature revision: They're more like guidelines anyway. Published Clinical anatomy. 2019.

[28] Tresguerres FGF, Torres J, López-Quiles J, Hernández G, Vega JA, Tresguerres IF. The osteocyte: A multifunctional cell within the bone Ann Anat. 2020 Jan; 227: 151422.

[29] Rydze R, Schutt A, Gibbons W, Nodler J. Gravity and Embryo Development. Curr Obstet Gynecol Rep. 2017; 6: 5154.

[30] Wang JH, Thampatty BP. An introductory review of cell mechanobiology. 2006. Biomech Model Mechanobiol. 2006; 5: 1-16.

[31] Suchacki KJ, Roberts F, Lovdel A, Farquharson C, Morton NM, MacRae VE, Cawthorn WP. Skeletal energy homeostasis: a paradigm of endocrine discovery. J Endocrinol. Jul 2017; 234(1): R67-R79.

[32] Woronowicz KC, Schneider RA. Molecular and cellular mechanisms underlying the evolution of form and function in the amniote jaw. Evodevo. 2019; 10: 17.

[33] Harley 0J, Pickford MA. CT analysis of fat distribution superficial and deep to the Scarpa's fascial layer in the mid and lower abdomen. J Plast Reconstr Aesthet Surg. 2013; 66(4):525-530.

[34] Han Y, You X, Xing W, Zhang Z, Zou W. Paracrine and endocrine actions of bone-the functions of secretory proteins from osteoblasts, osteocytes, and osteoclasts. Bone Res. 2018; 6: 16.

[35] Suchacki KJ, Roberts F, Lovdel A, Farquharson C, Morton NM, MacRae VE, Cawthorn WP. Skeletal energy homeostasis: a paradigm of endocrine discovery. J Endocrinol. Jul 2007; 234(1): R67-R79.

[36] Idelevich A, Baron R. Brain to bone: What is the contribution of the brain to skeletal homeostasis? Bone. 2008; 115: 31-42. 
[37] Jones KB, Mollano AV, Morcuende JA, Cooper RR, Saltzman CL. Bone and brain: a review of neural, hormonal, and musculoskeletal connections. Iowa Orthop J. 2004; 24: 123-132.

[38] Nuhoglu A, Korkmaz KA. A practical approach for nonlinear analysis of tensegrity systems. Engineering with Computers. 2011; 27: 337-345.

[39] Sharkey J. Biotensegrity-Anatomy for the 21st Century Informing Yoga and Physiotherapy Concerning New Findings in Fascia Research. Journal of Yoga and Physiotherapy. 2018; 6(1).

[40] Petros C. Benias, Rebecca G. Wells, et al. Structure and Distribution of an Unrecognised Interstitium in Human Tissues. Scientific Reports. 8: 49472018

[41] Boskey AL. Bone composition: relationship to bone fragility and antiosteoporotic drug effects [published correction appears in Bonekey Rep. 2015; 4: 710.

[42] Kumka M, Bonar J. Fascia: a morphological description and classification system based on a literature review. J Can Chiropr Assoc. 2012; 56(3): 179-191.

[43] Levin S. The Importance of Soft Tissues for Structural Support of the Body. Spine: State of the Art Reviews. 1995; $9(2)$.

[44] Bordoni B, Myers T. A Review of the Theoretical Fascial Models: Biotensegrity, Fascintegrity, and Myofascial Chains. Cureus. 2020; 12(2): e7092.

[45] Levin S. 16. Tensegrity, The New Biomechanics. In Hutson, Michael; Ward, Adam (eds.). Oxford Textbook of Musculoskeletal Medicine. Oxford University Press. 2015; P:155-156. 158-160.

[46] Scheinpflug J, Pfeiffenberger M, Damerau A, et al. Journey into Bone Models: A Review. Genes (Basel). 2018; 9(5): 247.

[47] Bordoni B, Lagana MM. Bone Tissue is an Integral Part of the Fascial System. Cureus. 2019; 11(1): e3824.

[48] Sharkey J. Biotensegrity-Fascia and the fallacy of biomechanics. Journal of Australian Association of Massage therapists. 2015. Summer Ed.

[49] Scarr, G. Biotensegrity-the structural basis of life, 2nd edition. 2018 Handspring Publishing. 